\title{
Increased Time in Range and Fewer Missed Bolus Injections After Introduction of a Smart Connected Insulin Pen
}

\author{
Peter Adolfsson, MD, PhD, ${ }^{1,2}$ Niels Væver Hartvig, MSc, $\mathrm{PhD}^{3}$ Anne Kaas, MD, PhD, \\ Jonas Bech Møller, MSc, $\mathrm{PhD}^{5}$ and Jarl Hellman, $\mathrm{MD}^{6}$
}

\begin{abstract}
Background: This observational study investigated whether the connected NovoPen ${ }^{\circledR} 6$ could influence insulin regimen management and glycemic control in people with type 1 diabetes (T1D) using a basal-bolus insulin regimen and continuous glucose monitoring in a real-world setting.

Methods: Participants from 12 Swedish diabetes clinics downloaded pen data at each visit (final cohort: $n=94$ ). Outcomes included time in range (TIR; sensor glucose 3.9-10.0 mmol/L), time in hyperglycemia ( $>10 \mathrm{mmol} / \mathrm{L})$, and hypoglycemia (L1: $3.0-<3.9 \mathrm{mmol} / \mathrm{L} ; \mathrm{L} 2:<3.0 \mathrm{mmol} / \mathrm{L})$. Missed bolus dose (MBD) injections were meals without bolus injection within -15 and +60 min from the start of a meal. Outcomes were compared between the baseline and follow-up periods ( $\geq 5$ health care professional visits). Data were analyzed from the first 14 days following each visit. For the TIR and total insulin dose analyses $(n=94)$, a linear mixed model was used, and for the MBD analysis $(n=81)$, a mixed Poisson model was used.

Results: TIR significantly increased $\left(+1.9[0.8 ; 3.0]_{95 \% \mathrm{CI}} \mathrm{h} /\right.$ day; $\left.P<0.001\right)$ from baseline to follow-up period, with a corresponding reduction in time in hyperglycemia $\left(-1.8[-3.0 ;-0.6]_{95 \% \mathrm{CI}} \mathrm{h} /\right.$ day; $\left.P=0.003\right)$ and L2 hypoglycemia $\left(-0.3[-0.6 ;-0.1]_{95 \% \mathrm{CI}} \mathrm{h} /\right.$ day; $\left.P=0.005\right)$, and no change in time in L1 hypoglycemia. MBD injections decreased by $43 \%$ over the study $(P=0.002)$. Change in MBD injections corresponded to a decrease from $25 \%$ to $14 \%$ based on the assumption that participants had three main meals per day.

Conclusions: Our study highlights the potential benefit on glycemic control and dosing behavior when reliable insulin dose data from a connected pen contribute to insulin management in people with T1D.
\end{abstract}

Keywords: Connected insulin pen, Time in range, Adherence, Hypoglycemia, Glycemic control.

\section{Introduction}

G LOBALLY, REGARDLESS OF DIABETES TYPE, many people treated with insulin struggle to take their medication on time and also maintain their treatment regimen over extended periods of time. ${ }^{1-4}$ Difficulties with insulin dosing and inaccurate dose timing have been shown to result in poor glycemic control for people with diabetes. ${ }^{5,6}$ The impact of missed insulin injections on $\mathrm{HbA}_{1 \mathrm{c}}$ levels is well established, ${ }^{7-12}$ leading to an increasing risk of diabetes-related complications. ${ }^{13,14}$
Technological advances offer opportunities to optimize insulin delivery, reduce dosing errors, and improve regimen management. Diabetes treatment and care is moving toward accurate, real-time, high-quality data that are easily available to people with diabetes and health care professionals (HCPs). In the era of smart phones, connected continuous glucose monitoring (CGM) systems, and activity trackers, advancements in insulin pen device design is part of the future. Connected pens have the added ability to record insulin dose data, thereby improving convenience. The use of connected

\footnotetext{
${ }^{1}$ Department of Pediatrics, The Hospital of Halland, Kungsbacka, Sweden.

${ }^{2}$ Institute of Clinical Sciences, Sahlgrenska Academy at University of Gothenburg, Gothenburg, Sweden.

${ }^{3}$ Data Science, ${ }^{4}$ Medical \& Science, and ${ }^{5}$ Digital Health, Novo Nordisk A/S, Søborg, Denmark.

${ }^{6}$ Department of Medical Sciences, Uppsala University, Uppsala, Sweden.
}

(c) Peter Adolfsson, et al., 2020; Published by Mary Ann Liebert, Inc. This Open Access article is distributed under the terms of the Creative Commons License (http://creativecommons.org/licenses/by/4.0), which permits unrestricted use, distribution, and reproduction in any medium, provided the original work is properly credited. 
insulin pens alongside CGM may have the potential to facilitate and improve diabetes management.

Two types of CGM systems are available for diabetes selfmanagement: real-time CGM (rtCGM) and intermittently scanned CGM (isCGM; also referred to as flash glucose monitoring). CGM, including isCGM (hereafter, unless stated, CGM includes both rtCGM and isCGM), is being used by an increasing number of people with type 1 diabetes (T1D). ${ }^{15,16}$

The key benefits of CGM include real-time data monitoring for people with T1D and access for them and their HCPs to complete glucose datasets ${ }^{17}$; both of which help people to achieve their target time spent within the acceptable range (time in range [TIR]: $3.9-10.0 \mathrm{mmol} / \mathrm{L}$ [70-180 $\mathrm{mg} / \mathrm{dL}]$ ) and avoid hyper- and hypoglycemia. ${ }^{18}$ Reductions in $\mathrm{HbA}_{1 \mathrm{c}}$ have been reported with CGM use in people on multiple daily injection (MDI) therapy, ${ }^{19}$ and continuous subcutaneous insulin infusion therapy, ${ }^{20}$ with reduced time spent in hypoglyce$\mathrm{mia}^{20}$ and improved hypoglycemia awareness. ${ }^{21}$

The connected insulin pen, NovoPen ${ }^{\circledR} 6$, administers insulin in $1 \mathrm{U}$ dose increments, with a maximum dose of up to $60 \mathrm{U}$. The number of units of the last administered insulin dose and the time elapsed since administration is shown on an electronic display. The NovoPen ${ }^{\circledR} 6$ has a 5 -year battery life, and collects and stores data on the date and time of injections and the number of units administered; these can be downloaded, using near field connectivity, to a centralized database on a computerbased data visualization program such as diasend ${ }^{\circledR}$ (Glooko, Inc., CA). These data allow both users and HCPs to access and visualize insulin injection patterns over time, together with the information from home blood glucose meters and/or CGMs.
The connected NovoPen ${ }^{\circledR} 6$ has the potential to move dialogues regarding diabetes management with HCPs away from guessing about administered doses, toward true knowledge about missed doses, optimal injection time, and optimal dose size in relation to meals when combined with CGM. This could create a more complete picture of the current glycemic control, treatment, and disease state for people with T1D and HCPs. Therefore, the aim of this observational study was to investigate whether the connected NovoPen ${ }^{\circledR} 6$ could influence insulin regimen management and glycemic control in people with T1D using CGM in a real-world setting.

\section{Methods}

\section{Study design and participants}

This study was a one-arm, prospective, observational, proofof-concept study, including 12 diabetes clinics in Sweden from May 2017 until April 2019. For the analyses presented here, study data from May 2017 to October 2018 only were used. Participants were continuously enrolled into the study from initiation until the complete data set was downloaded from the Glooko database. Swedish Ethics Committee approval (201901270) was obtained before any study-related activities. Written informed consent was obtained from each participant by Glooko, allowing Glooko to collect the participant's data and share it with Novo Nordisk for scientific purposes.

People with T1D using CGM, from the participating diabetes clinics, were included in the study at the discretion of their treating physician. At baseline, participants received a NovoPen ${ }^{\circledR} 6$ for basal and/or bolus insulin injections.
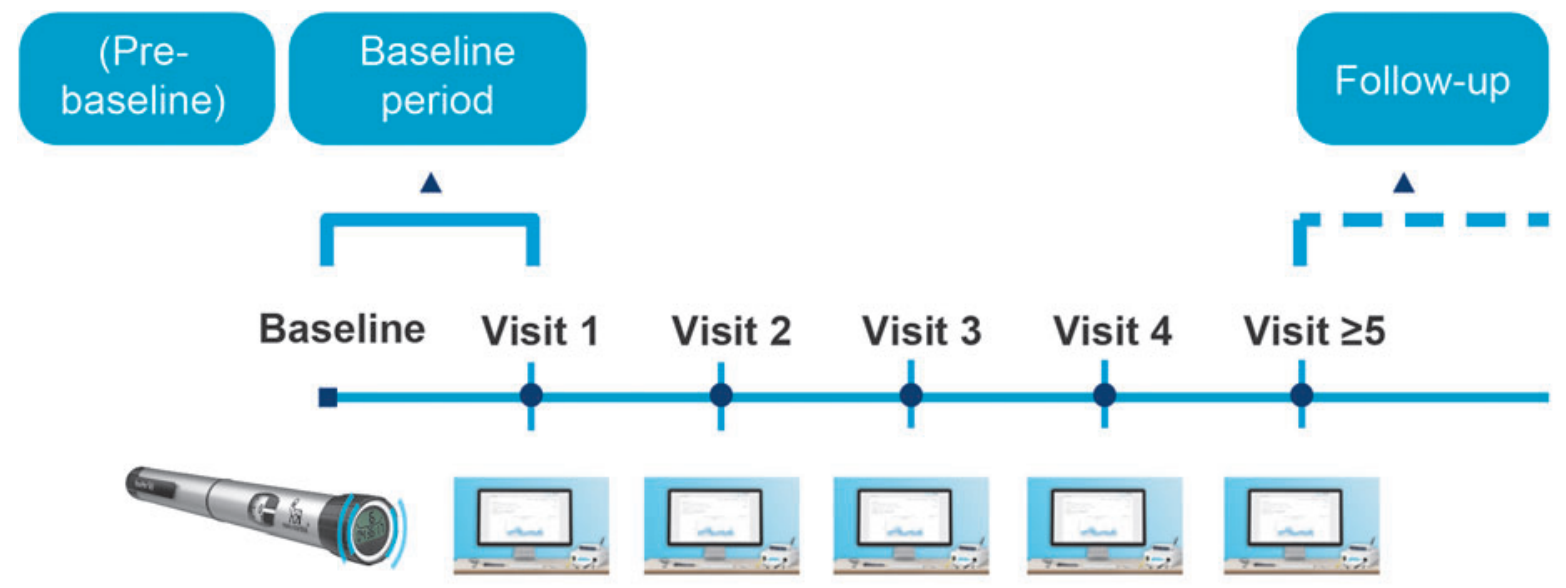

Insulin dose, time and date

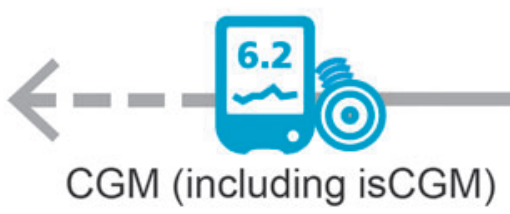

FIG. 1. Study design. Prebaseline was the period before study commencement where participants were already using CGM, but without concurrent use of the NovoPen ${ }^{\circledR}$ 6. CGM, continuous glucose monitoring; isCGM, intermittently scanned continuous glucose monitoring. 
Participants were blinded to the injection data overview during the baseline period (baseline until visit 1; Fig. 1). However, participants could still see their CGM data and they could also see the dose of their last injection displayed on the pen.

At visit 1, the first set of injection data were downloaded at the clinic for discussion between the participant and HCP. As there is no difference in the operation of the NovoPen ${ }^{\circledR} 6$ compared with traditional durable pens, except for connectivity features, participants did not receive any structured education or training; individual centers may have provided informal training on the connectivity component of the pen at, or after, the first visit. Thereafter, follow-up visits were scheduled according to usual clinical practice; at each visit, pen and CGM data were downloaded, discussed and acted upon by the participant and HCP. CGM data were also uploaded between visits (Figs. 1 and 2).

Pen data could only be downloaded at the HCP's office (i.e., not at a participant's home). Data were downloaded from the Glooko database with anonymized participant IDs; data were then cleaned to ensure consistency and to avoid duplication (as detailed in the Results section).

\section{Outcomes}

Glycemic summary measures and number of missed bolus dose (MBD) injections were compared between the blinded baseline period and a follow-up period. The follow-up period was defined as any point after the fifth $\mathrm{HCP}$ visit. Visit 5 was chosen as the earliest point for follow-up, as participants would on average have been in the study for $\geq 180$ days, allowing for sufficient interaction with HCPs and discussion of available pen data. Days from baseline to visit 5 (Q1, median, and Q3) were 167, 196, and 260.

TIR was defined as the time spent with sensor glucose within the acceptable range $(3.9-10.0 \mathrm{mmol} / \mathrm{L}$ [70-180 $\mathrm{mg} / \mathrm{dL}])$. Additional outcomes included time spent in hyperglycemia $(>10.0 \mathrm{mmol} / \mathrm{L}[>180 \mathrm{mg} / \mathrm{dL}])$ and time spent in hypoglycemia, split into Level 1 (L1: $3.0-<3.9 \mathrm{mmol} / \mathrm{L}[54-<70 \mathrm{mg} / \mathrm{dL}])$ and Level 2 (L2: $<3.0 \mathrm{mmol} / \mathrm{L}[<54 \mathrm{mg} / \mathrm{dL}]$ ). In addition, the total daily insulin (basal/bolus) dose, mean glucose level, and the coefficient of variation were measured. ${ }^{22}$ MBD was defined as meals with no bolus injection within a time window of $15 \mathrm{~min}$ before to $60 \mathrm{~min}$ after the start of a meal, as detected from the CGM signal by the clinically validated Glucose Rate Increase Detector (GRID) algorithm (Fig. 3). ${ }^{23}$ An "on-time", dose was defined as when a bolus insulin injection was detected within $15 \mathrm{~min}$ before and $60 \mathrm{~min}$ after the start of a meal.

Meals were detected when the CGM signal was $\geq 7.2 \mathrm{mmol} / \mathrm{L}(\geq 130 \mathrm{mg} / \mathrm{dL})$ and the rate-of-change was $\geq 5.3 \mathrm{mmol} /(\mathrm{L} \cdot \mathrm{h})[\geq 95 \mathrm{mg} /(\mathrm{dL} \cdot \mathrm{h})]$ for the last two consecutive readings, or $\geq 5.0 \mathrm{mmol} /(\mathrm{L} \cdot \mathrm{h})[\geq 90 \mathrm{mg} /(\mathrm{dL} \cdot \mathrm{hour})]$ for two of the last three readings. The majority of participants used isCGM, which registered readings every $15 \mathrm{~min}$. Therefore, the rtCGM signals, which registered readings

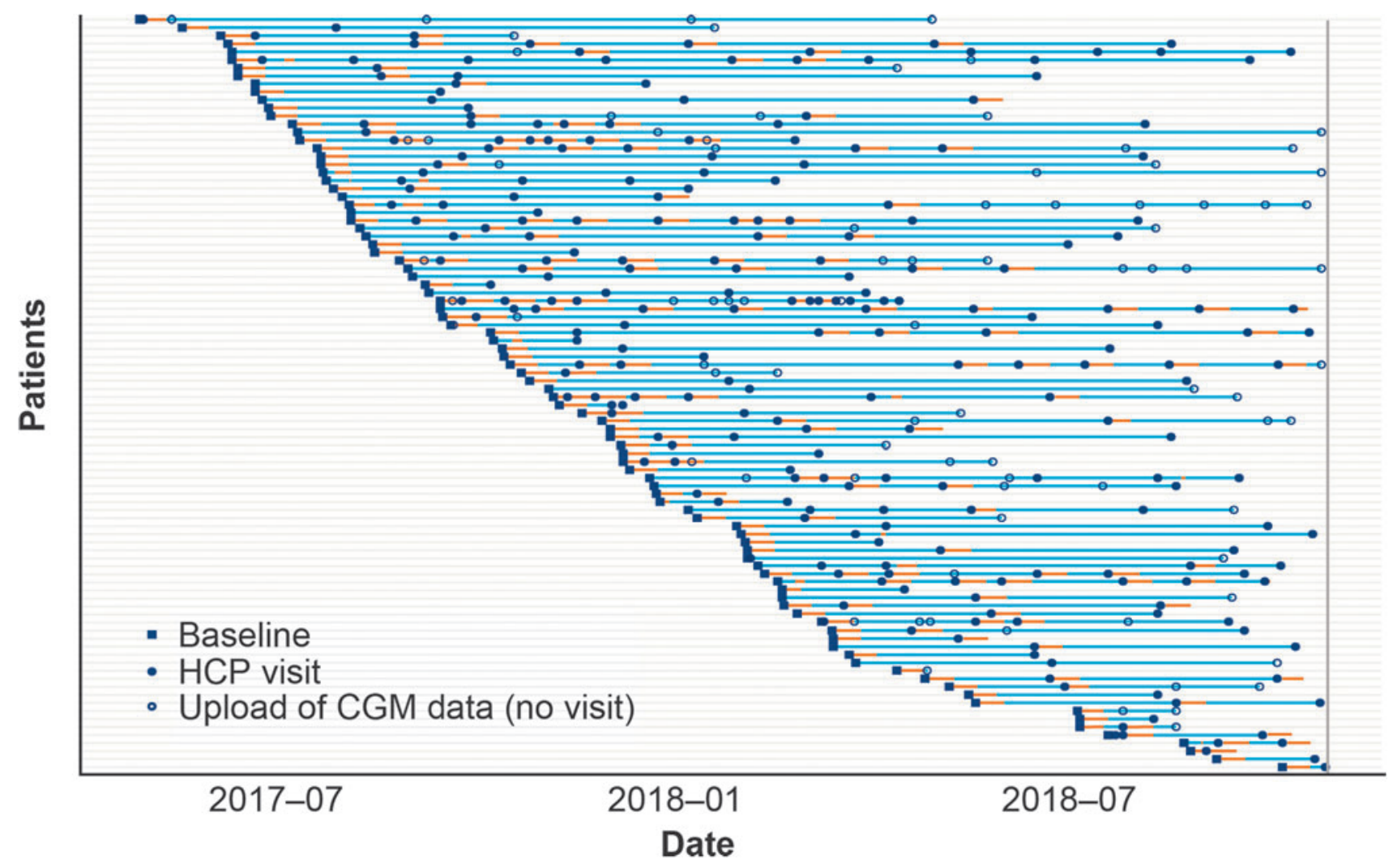

FIG. 2. Upload of participant CGM data. Study period for each participant. A total of 94 participants are included in the TIR analysis. Blue lines indicate the period where data are available from the baseline date (blue square) to the last date with either CGM or insulin dosing data in the database. The filled blue circles indicate visits to the clinic, where data were downloaded and evaluated with the HCP. Orange lines indicate days with acceptable CGM data* within 1-14 days that are included in the primary analysis. The open blue circles are virtual uploads of CGM data that were not physical HCP visits. *CGM coverage of at least $70 \%$ per day. CGM, continuous glucose monitoring; HCP, health care professional; TIR, time in range. 

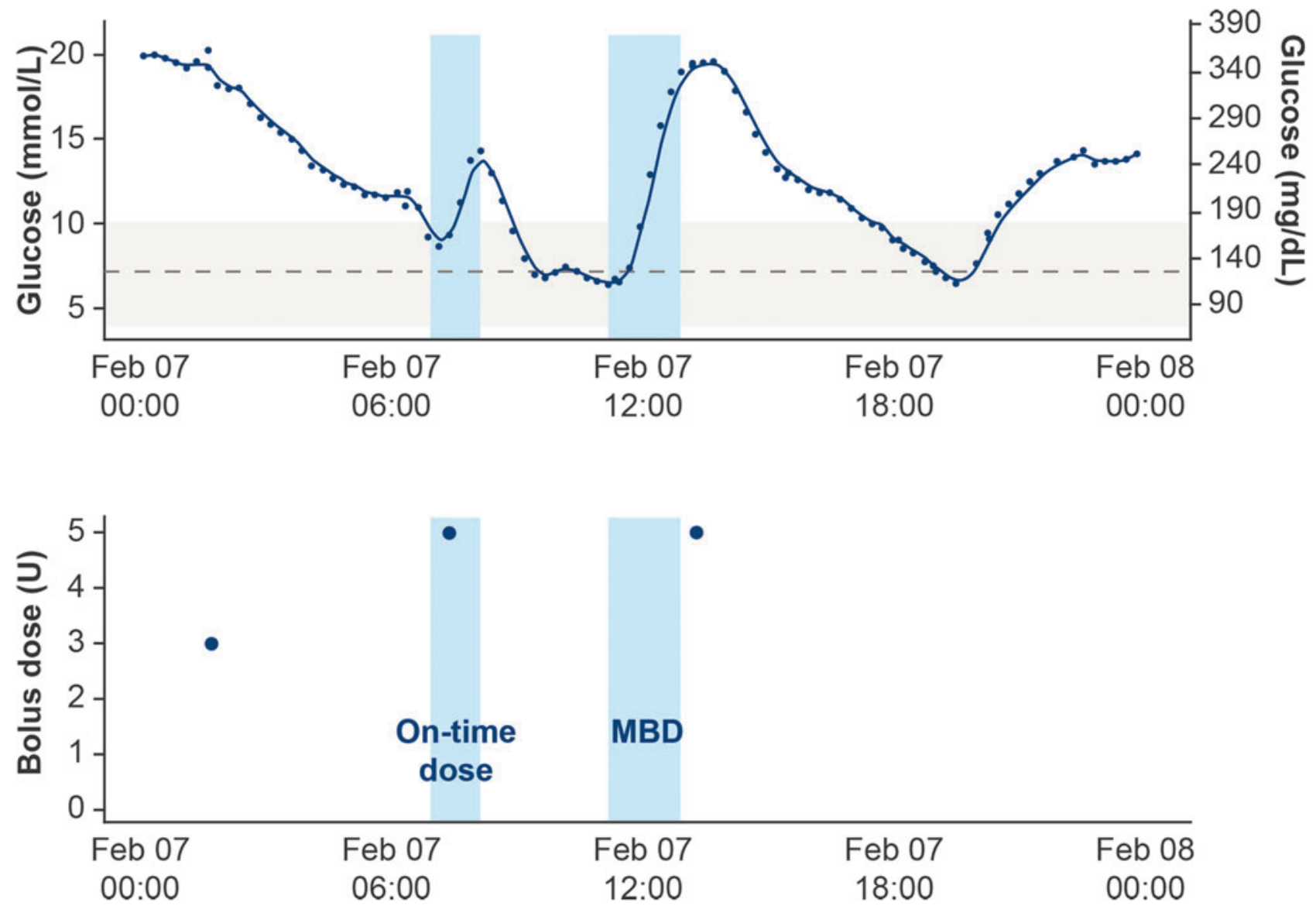

FIG. 3. Detection of missed bolus insulin doses by the GRID algorithm. Example of a day with two meals detected. The solid dark blue line represents the CGM signal and the light blue shaded areas each represent a detected meal. The gray, dashed line represents a glucose level of $7.2 \mathrm{mmol} / \mathrm{L}(130 \mathrm{mg} / \mathrm{dL})$ and the gray shaded area represents a target glycemic range of $3.9-10.0 \mathrm{mmol} / \mathrm{L}(70-180 \mathrm{mg} / \mathrm{dL})$. Meals are detected when the CGM signal is $\geq 7.2 \mathrm{mmol} / \mathrm{L}(\geq 130 \mathrm{mg} / \mathrm{dL})$ and with rate-of-change being sufficiently high over the last two to three readings corresponding. The blue circles in the lower figure indicate bolus doses. A bolus dose within $15 \mathrm{~min}$ before to $60 \mathrm{~min}$ after a meal starts is considered "on-time," whereas a dose outside of this time window is considered a MBD. Male patient, aged 30 at baseline. CGM, continuous glucose monitoring; GRID, Glucose Rate Increase Detector; MBD, missed bolus dose.

every $5 \mathrm{~min}$, were resampled to $15 \mathrm{~min}$ intervals. CGM profiles typically did not display all three meals per day, possibly due to low-carbohydrate or well-dosed meals that were indistinct in the CGM signal to the GRID algorithm. This was due to the algorithm being designed to detect meals that contained at least $40 \mathrm{~g}$ of carbohydrate.

\section{Statistical analyses}

Data from the first 14 days following each clinic visit were used in the analyses in line with the international consensus on the use of CGM. ${ }^{22}$ Days with unacceptable CGM coverage $(<70 \%)$ were excluded. Approximately, 2500 days' worth of CGM data with acceptable coverage were included.

Due to the variation in study duration and visit frequency observed between participants (Fig. 2), an initial analysis investigating whether there was a relationship between baseline participant characteristics and the variations in study duration and visit frequency was conducted.

TIR values were calculated both in hours, based on the time interval between readings, and as a percentage of all readings on a given day. Slight differences in the results from these two methods were expected due to sections with missing data or additional isCGM readings obtained when manually scanning the sensor.

For the TIR and total insulin dose analysis $(n=94)$, each day was aggregated to a single value for each response. A linear mixed model was applied with visit number (baseline, 1, 2, 3, $4,5+)$ as fixed effect and participant and visit nested within participant as random effects. An exponential covariance function was used to model the correlation between days within a 14-day period. All 94 participants with acceptable CGM data were included in the analysis, and a total of 14 participants contributed with data from visit 5 or later (Supplementary Fig. S1).

All data from all participants were included in the analysis, as the linear mixed model allowed for unbalanced and missing data. Robustness with respect to the choice of followup period was evaluated by estimating the change from baseline for each single visit. The estimated difference between baseline and the follow-up period was obtained with 95\% confidence intervals. The dosing data were analyzed on a logarithmic scale and estimates and confidence intervals converted to relative differences in percent. 
For the MBD injection analysis, this was restricted to participants with bolus pen data $(n=81)$. The change in the mean number of MBD injections from baseline to the followup period (after five HCP visits) was analyzed using a generalized linear mixed model based on the Poisson distribution with visit number (baseline, 1, 2, 3, 4, 5+) as fixed effect, and participant and visit nested in participant as random effects, and using a logarithmic link-function. As for the TIR analysis, all 81 participants were included in the analysis. The number of participants achieving $\geq 5$ visits was 10 . Robustness with respect to the choice of follow-up period was evaluated by estimating the change from baseline for every visit.

A significance level of $P<0.05$ was predefined for all statistical comparisons. All statistical models were verified based on residual plots (not shown).

\section{Results}

\section{Study population}

A total of 270 participants' IDs were downloaded from the Glooko database. However, some of the dose records in the database were duplicates from the same pen registered under different participant IDs, indicating that some participants had registered with multiple IDs (i.e., multiple e-mail addresses). Participant IDs sharing the same pen had to be relinked and inconsistent IDs or those IDs with unusable data were excluded, resulting in 224 participants remaining in the cohort.

Participant IDs were excluded from the cohort if they did not have both CGM and pen data, if they were children $<18$ years of age or if they did not have CGM data within 14 days of a visit. Children and adolescents were excluded from the analyses; some children had additional functionality to upload data from home, which meant that a clear link between upload points and clinic visits could not be established. This resulted in a final cohort of 94 participants, representing 35\% of participant IDs received, included in the main analyses.

Of these 94 participants, 48 were men and 46 were women, with a mean age of 40.1 years (range $18-83$ years). Eleven participants used CGM with 5 min intervals between readings and 83 used isCGM with 15 min intervals between readings. A total of 64 participants used NovoPen ${ }^{\circledR} 6$ for bolus insulin only, 17 for both basal and bolus insulin, and 5 for basal insulin only ( 7 participants did not have connected pen data in the 14-day period following a visit and 1 participant used biphasic insulin aspart 30, which is neither bolus nor basal insulin). The majority of participants with a basal insulin pen used insulin degludec $(n=21)$, with one participant using insulin detemir. Of participants with a bolus insulin pen, a total of 79 used insulin aspart as the bolus insulin, with one participant using human insulin and one participant using faster-acting insulin aspart.

The average study duration (the number of days from baseline to the last day with any relevant data [CGM or pen] before the download date from Glooko) was 223 days (range 14-487 days), with a mean of 27 days' data included per participant from day 1 to 14 after a visit. Visit frequency and time between visits varied between participants, as visits were scheduled according to clinical practice (mean number of visits in the study: 2.6 visits [range $0-11$ visits]; mean time between visits: 71 days [range 1-319 days]). There was no indication of a relationship between baseline parameters (age, glycemic control, or insulin dose) and study duration or visit frequency.

\section{Glycemic summary measures and insulin dosing}

Of the final cohort of 94 participants, 14 made $\geq 5$ visits to a HCP (Supplementary Fig. S1). The number of participants with data at visits $1,2,3$, and 4 was $57,30,21$, and 15 , respectively. The change in TIR was relatively stable from visit 4 onward, as shown in Supplementary Figure S1. A significant absolute increase in mean TIR of $1.9[0.8 ; 3.0]_{95 \%} \mathrm{CI}$ hours per day $(P<0.001)$ or $8.5 \%$ (percent of day) [3.7; $13.3]_{95 \% \mathrm{CI}}(P<0.001)$ was reported, from baseline to after five HCP visits (Table 1 and Fig. 4). This corresponded to a relative increase of about $21 \%$ of the mean baseline level. Accordingly, there was a significant reduction in mean time spent in hyperglycemia $(>10.0 \mathrm{mmol} / \mathrm{L}[>180 \mathrm{mg} / \mathrm{dL}])$ of $-1.8[-3.0$; $-0.6]_{95 \%}$ CI hours per day $(P=0.003)$ or $-6.2 \%$ (percent of day) $[-11.5 ;-1.0]_{95 \%} \mathrm{CI}(P=0.021)$ (Table 1 and Fig. 4$)$.

Table 1. Baseline Level and Estimated Change at or After Five Health Care Professional Visits: Key Glycemic Summary Statistics

\begin{tabular}{|c|c|c|c|}
\hline & Baseline level [95\% CI] & Estimated change $[95 \% \mathrm{CI}]$ & $P$ \\
\hline TIR (3.9-10.0 mmol/L [70-180 mg/dL]) & $9.19 \mathrm{~h}[8.28 ; 10.10]$ & $1.89 \mathrm{~h}[0.79 ; 2.99]$ & $\begin{array}{l}<0.001 \\
<0.001\end{array}$ \\
\hline TIHyper $(>10.0 \mathrm{mmol} / \mathrm{L}[>180 \mathrm{mg} / \mathrm{dL}])$ & $\begin{array}{l}41.4 \%[37.4 ; 45.3] \\
11.80 \mathrm{~h}[10.81 ; 12.79]\end{array}$ & $\begin{array}{c}8.5 \%[3.7 ; 13.3] \\
-1.78 \mathrm{~h}[-2.96 ;-0.60]\end{array}$ & $\begin{array}{r}<0.001 \\
0.003\end{array}$ \\
\hline & $53.5 \%[49.0 ; 58.1]$ & $-6.2 \%[-11.5 ;-1.0]$ & 0.021 \\
\hline TIHypo L1 $(3.0-<3.9 \mathrm{mmol} / \mathrm{L}[54-<70 \mathrm{mg} / \mathrm{dL}])$ & $\begin{array}{c}0.69 \mathrm{~h}[0.55 ; 0.83] \\
3.1 \%[2.5 ; 3.7]\end{array}$ & $\begin{array}{l}-0.15 \mathrm{~h}[-0.36 ; 0.07] \\
-0.7 \%[-1.6 ; 0.2]\end{array}$ & $\begin{array}{l}0.181 \\
0.141\end{array}$ \\
\hline TIHypo L2 (<3.0 mmol/L [<54 mg/dL]) & $\begin{array}{c}0.47 \mathrm{~h}[0.32 ; 0.61] \\
2.1 \%[1.4 ; 2.7]\end{array}$ & $\begin{array}{l}-0.33 \mathrm{~h}[-0.56 ;-0.10] \\
-1.5 \%[-2.5 ;-0.5]\end{array}$ & $\begin{array}{l}0.005 \\
0.004\end{array}$ \\
\hline $\begin{array}{l}\text { Mean glucose } \\
\% \text { Coefficient of variation }\end{array}$ & $11.09 \mathrm{mmol} / \mathrm{L}[10.53 ; 11.65]$ & $-0.34 \mathrm{mmol} / \mathrm{L}[-0.96 ; 0.28]$ & $\begin{array}{l}0.279 \\
0.001\end{array}$ \\
\hline$\%$ Coefficient of variation & $35.89 \%[34.33 ; 37.45]$ & $-3.84 \%[-6.12 ;-1.56]$ & 0.001 \\
\hline
\end{tabular}

Estimated baseline level and change between visits $\geq 5$ and baseline with $95 \%$ CI. Linear mixed model of TIR per day, with visit number (baseline, 1, 2, 3, 4, 5+) as fixed effect, participant and visit nested in participant as random effects, and with exponential covariance function. $N=94$, visits $=231$, CGM days $=2552$. TIR values were calculated both in hours, based on the time interval between readings, and as a percentage of all readings on a given day. Slight differences in the results from these two methods may occur due; sections with missing data or additional CGM readings at the time of sensor scanning.

CGM, continuous glucose monitoring; CI, confidence interval; $N$, number; TIHyper, time in hyperglycemia; TIHypo L1, time in L1 hypoglycemia; TIHypo L2, time in L2 hypoglycemia; TIR, time in range. 


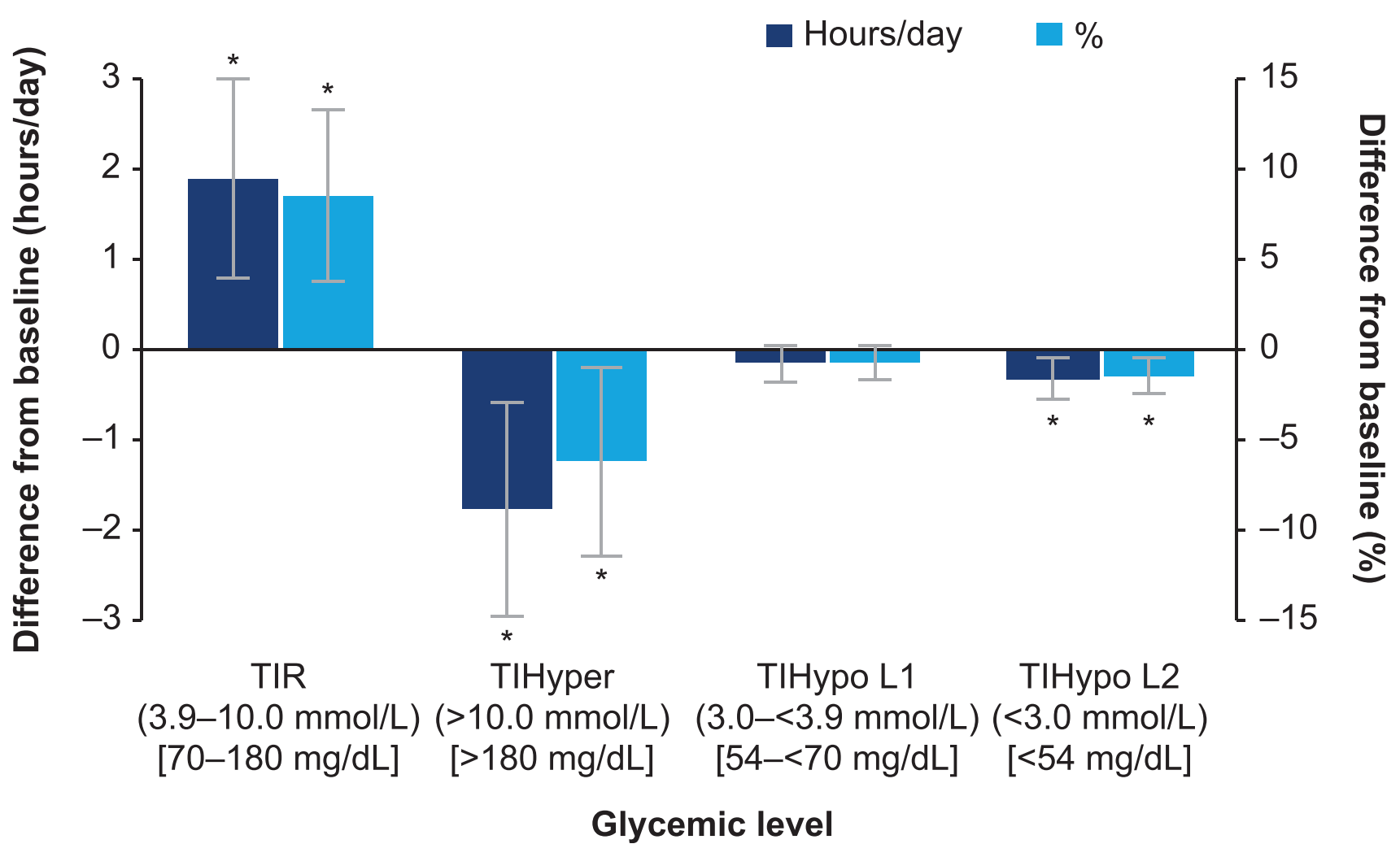

FIG. 4. Mean difference in the time spent in glycemic ranges from baseline to after five HCP visits. $* P<0.05$. Estimated mean difference in time spent in glycemic ranges with $95 \% \mathrm{CI}$. The difference is observed between baseline and $\geq 5 \mathrm{HCP}$ visits. Baseline is the period after treatment initiation but before the first visit. Analysis is based on CGM data from a 14-day interval after each visit ( $\geq 70 \%$ coverage). Patients $\geq 18$ years $(n=94)$ are included. CGM, continuous glucose monitoring; CI, confidence interval; HCP, health care professional; $n$, number; TIHyper, time in hyperglycemia; TIHypo L1, time in L1 hypoglycemia; TIHypo L2, time in L2 hypoglycemia; TIR, time in range.

There was no significant change in mean time spent in L1 hypoglycemia $(3.0-<3.9 \mathrm{mmol} / \mathrm{L}[54-<70 \mathrm{mg} / \mathrm{dL}] ; P=0.181$; Table 1 and Fig. 4). A significant reduction in L2 hypoglycemia $(<3.0 \mathrm{mmol} / \mathrm{L}[<54 \mathrm{mg} / \mathrm{dL}])$ of $-0.3[-0.6 ;-0.1]_{95 \% \mathrm{CI}}$ hours per day $(P=0.005)$ or $-1.5 \%$ (percent of day) $[-2.5$; $-0.5]_{95 \% \mathrm{CI}}(P=0.004)$ was also observed (Table 1 and Fig. 4). While the mean glucose level did not change significantly $\left(-0.34 \mathrm{mmol} / \mathrm{L}[-0.96 ; 0.28]_{95 \% \mathrm{CI}}\right)$, the coefficient of variation was significantly reduced by $3.8 \%[-6.1 ;-1.6]_{95 \% \mathrm{CI}}$ from a baseline level of $35.9 \%(P=0.001$; Table 1$)$.

In terms of bolus insulin dose $(n=81)$, there was a significant increase from baseline $\left(25.1 \mathrm{U} /\right.$ day $\left.[22.0 ; 28.7]_{95 \% \mathrm{CI}}\right)$ to after five HCP visits of $28 \%[9.4 ; 49.5]_{95 \% \text { CI }}(P=0.002)$. There was no significant change from baseline (24.2 U/day $\left.[19.8 ; 29.8]_{95 \% \text { CI }}\right)$ in mean basal insulin dose $(n=22$; change $\left.11 \%[-7.2 ; 32.8]_{95 \% \mathrm{CI}}, P=0.238\right)$.

\section{$M B D$ injections}

Eighty-one adults with T1D were included in the MBD analyses, which included 2747 detected meals; 10 participants in this analysis had $\geq 5$ visits. A significant decrease of $43 \%$ (estimated relative change: $-43.1 \%[-60.5 ;-18.0]_{95 \% \mathrm{CI}}$, $P=0.002$; Table 2) in the average daily number of MBD injections was observed from baseline $\left(0.74[0.62 ; 0.88]_{95 \% \mathrm{CI}}\right)$ to the follow-up period $\left(0.42[0.30 ; 0.60]_{95 \% \text { CI }}, P=0.002\right.$; Table 2 and Fig. 5). The change in MBD injections by visit is included in Supplementary Figure S2, which shows that a

Table 2. Mean Number of Daily Meals and Dosing Behaviors from Baseline to After Five Health Care Professional Visits

\begin{tabular}{|c|c|c|c|c|c|c|}
\hline & \multicolumn{2}{|c|}{ Baseline level [95\% CI] } & \multicolumn{2}{|c|}{ Visit $\geq 5$ level $[95 \%$ CI] } & \multirow[b]{2}{*}{$\begin{array}{l}\text { Estimated relative } \\
\text { change }[95 \% \mathrm{CI}]\end{array}$} & \multirow[b]{2}{*}{$\mathrm{P}$} \\
\hline & Daily meals (n) & $\begin{array}{l}\text { Proportion } \\
\text { of } 3 \text { meals }\end{array}$ & Daily meals (n) & $\begin{array}{l}\text { Proportion } \\
\text { of } 3 \text { meals }\end{array}$ & & \\
\hline $\mathrm{MBD}$ & $74[0.62 ; 0.88]$ & $24.7 \%[20.8 ; 29.4]$ & $0.42[0.30 ; 0.60]$ & $14.1 \%[9.9 ; 19.9]$ & $-43.1 \%[-60.5 ;-18.0]$ & 0.002 \\
\hline "On-time" dose & $0.57[0.48 ; 0.69]$ & $19.1 \%[15.9 ; 23.0]$ & $0.59[0.43 ; 0.80]$ & $19.6 \%[14.5 ; 26.7]$ & $2.7 \%[-24.7 ; 40.2]$ & 0.865 \\
\hline Undetected meals $^{\mathrm{a}}$ & $1.54[1.37 ; 1.70]$ & $51.5 \%[45.6 ; 56.7]$ & $1.94[1.69 ; 2.14]$ & $64.6 \%[56.4 ; 71.2]$ & $25.4 \%[8.7 ; 43.5]$ & 0.003 \\
\hline
\end{tabular}

Estimated mean data and 95\% CI based on a mixed Poisson model, with visit number (baseline, 1, 2, 3, 4, 5+) as fixed effect and participant and visit nested in participant as random effects.

${ }^{a}$ Assuming three meals per day on average.

$\mathrm{CI}$, confidence interval; $\mathrm{HCP}$, health care professional; MBD, missed bolus dose; $\mathrm{N}$, number. 


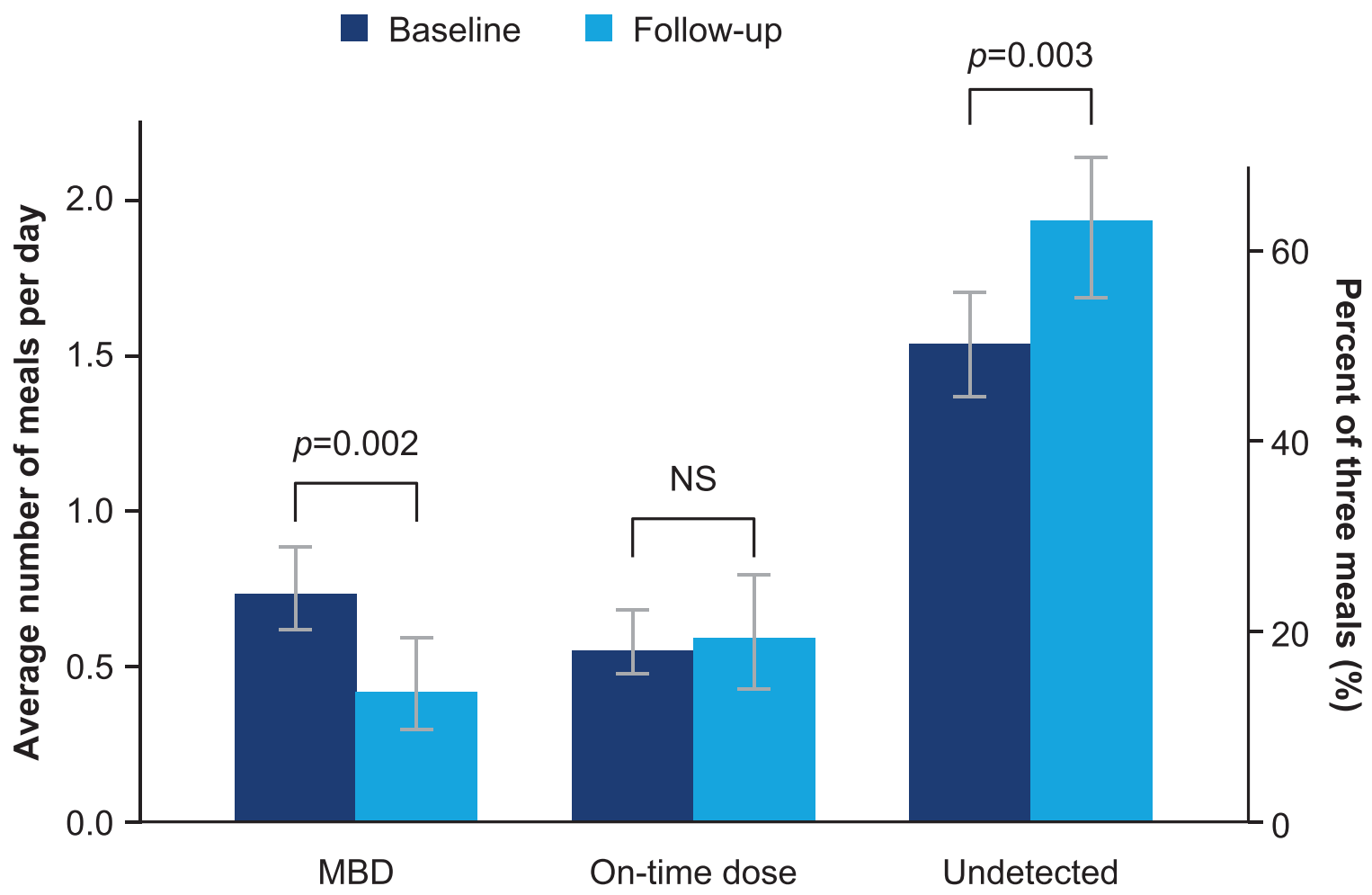

FIG. 5. Mean number of daily meals and dosing behaviors from baseline to after 5 HCP visits. Estimated mean number of daily meals with $95 \%$ CI. MBD are meals with missed bolus doses. "On-time" doses are meals where a bolus dose is taken. Undetected are meals that are not detected by the CGM signal, assuming an average of three meals per day. CGM, continuous glucose monitoring; CI, confidence interval; HCP, health care professional; MBD, missed bolus dose; NS, not significant.

significant effect was seen from visit 3 , and that it was relatively consistent from this point onward. Based on the assumption that participants have three main meals per day, the change in daily number of MBD injections corresponded to a decrease from $24.7 \%$ [20.8; 29.4 $]_{95 \% \text { CI }}$ (five meals with a missed dose per week) to $14.0 \%[9.9 ; 19.9]_{95 \% \mathrm{CI}}$ (three meals with a missed dose per week) in MBD injections.

\section{Discussion}

Many people treated with insulin fail to reach their glycemic targets, which is known to increase the risk of microvascular and macrovascular complications, resulting in substantial morbidity and mortality. ${ }^{13,14,24}$ Our findings in this observational study in adults with T1D using CGM highlight the potential benefits on glycemic control and injection behavior when connected pen data contribute to insulin treatment. Previous studies have identified that an engaging and open dialogue between HCPs and people with T1D is highly important for optimal disease management, as it promotes collaboration, communication, and people's participation in their own treatment decisions. ${ }^{25,26}$ Our results suggest that the use of a connected pen might help to facilitate more informed dialogues between HCPs and people with T1D.

Over the course of the study, participants experienced less glucose variability, more TIR and less time in hyperglycemia and L2 hypoglycemia $(<3.0 \mathrm{mmol} / \mathrm{L}[<54 \mathrm{mg} / \mathrm{dL}])$; these changes occurred early, after five visits with a HCP. The recent Advanced Technologies \& Treatments for Diabetes Congress consensus recommendations suggest that an ap- proximate $5 \%$ increase in TIR is associated with clinically significant benefits. ${ }^{27}$ Two analyses found that an increase in TIR of $10 \%$ corresponded to a decrease in $\mathrm{HbA}_{1 \mathrm{c}}$ of $\sim 0.5 \%$ $0.8 \%$ (5-9 mmol/mol). ${ }^{28,29}$ Therefore, even small improvements in TIR can yield corresponding improvements in $\mathrm{HbA}_{1 \mathrm{c}}$, and result in clinically significant benefits. Based on these analyses, the $8.5 \%$ increase in TIR reported here would be expected to correspond to an improvement in $\mathrm{HbA}_{1 \mathrm{c}}$ of $\sim 0.4-0.7 \%(4-7 \mathrm{mmol} / \mathrm{mol})$.

Notably, in the current study, time in hypoglycemia did not increase, while time in $\mathrm{L} 2$ hypoglycemia $(<3.0 \mathrm{mmol} / \mathrm{L}$ $[<54 \mathrm{mg} / \mathrm{dL}])$ decreased. Mean glucose levels showed only a slight, but nonsignificant, decrease $\left(\mathrm{HbA}_{1 \mathrm{c}}\right.$ data were not recorded). However, glucose variability decreased significantly, indicating that the improved TIR was primarily due to more consistent and stable glucose levels (CGM profiles) rather than a general reduction across the day. The significant increase in the injected bolus dose from baseline to the follow-up period $(28 \%)$ may have contributed to the improved TIR and stable profiles.

The finding of only a small, nonsignificant, increase in basal dose may be due to relatively few participants in the study using connected pens for their basal insulin. A previous study has demonstrated that improvements in glycemic control and glycemic variability were associated with an increased frequency of blood glucose testing and administration of bolus insulin. ${ }^{30}$ Other studies have demonstrated that fluctuations in blood glucose levels may contribute more to outcomes than constant high blood glucose concentrations. $^{31-35}$ As measurements of $\mathrm{HbA}_{1 \mathrm{c}}$ do not reflect glycemic variability and target $\mathrm{HbA}_{1 \mathrm{c}}$ values may be achieved 
while still experiencing marked daily glycemic fluctuations, people with T1D may regard reducing glucose variability and improving TIR to be as important as achieving their target $\mathrm{HbA}_{1 \mathrm{c}}$ value. ${ }^{36,37}$

The study data also confirmed that missing bolus injections can be common for people with T1D, where on average at least $25 \%$ of meals had a missed dose, assuming three meals per day. This amounts to five meals with a missed dose per week on average. Supporting people to engage with and optimize their insulin regimens is a key challenge for HCPs, with educational interventions having limited effects. ${ }^{38}$ Studies have found significant correlations between $\mathrm{HbA}_{1 \mathrm{c}}$ levels and the number of missing bolus injections. ${ }^{7,39}$ A recent study observed that the rate of late or missed bolus injections was $27 \%$ in people using MDI therapy, and that missed bolus injections correlated with higher $\mathrm{HbA}_{1 \mathrm{c}}$ levels. ${ }^{40}$ In a study of youths receiving insulin pump therapy, two missed bolus injections each week was associated with an increase in $\mathrm{HbA}_{1 \mathrm{c}}$ of $0.5 \%(5 \mathrm{mmol} / \mathrm{mol}){ }^{39}$

Our findings indicate that a connected pen may help people to reduce the number of missed bolus injections and to properly adjust doses, thus leading to better glycemic control. Participants in our study achieved a greater number of welldosed meals, with $43 \%$ fewer meals with missed doses through connected pen use. This suggests that evaluating past dosing data together with HCPs may have helped participants to remember and administer their meal-time doses, or to improve the timing of the dose relative to the meal. Taken together, our TIR and MBD data support the hypothesis that connected pens may support people with the management of their insulin treatment regimens.

Observational studies have inherent limitations, which should be considered when interpreting our results. As this was a short single-arm study, we cannot conclude with certainty that the use of a connected pen directly improved glycemic control, and other factors may have played a role. We are confident that the effect seen was not due to the use of CGM alone; an analysis of a subset of participants with confirmed CGM data in the database, at least 3 weeks before baseline (i.e., existing CGM users), demonstrated virtually the same results (data not shown). Longer studies are warranted to adequately assess effect durability.

Since visits were conducted according to local clinical practice, the time in study, number of HCP visits, and time between visits varied considerably between participants. This may have resulted in a selection bias; however, data analyses did not find any evidence of relationships between baseline participant characteristics and study time or visit frequency. In addition, the visit frequency for most participants seemed to be higher than what would be expected in normal clinical practice. ${ }^{41}$ Participants may have been more engaged in their glucose profiles and insulin dose patterns and therefore visited their HCPs more frequently to download and discuss their glucose and insulin dosing data. Equally, this may be explained by the initial need for more frequent visits when introducing a new technology. Further investigation of the effect of at-home data download capacity on visit frequency might permit digital consultations and reduce the need for clinic visits.

There was limited access to background participant information within the dataset, such as diabetes status and comorbidities. Many participant IDs (65\%) were excluded from the analyses during data cleaning. Furthermore, as data were unbalanced, the use of a linear mixed model with different levels of correlations was necessary. ${ }^{42}$ This allowed all data to be used, and by including participant as a random effect, it ensured that each participant had their own baseline level, and the estimated change from baseline to visit 5 can be interpreted as the mean change from this level. For the TIR analysis, only 14 participants had data from visit 5 onward (Supplementary Fig. S1), meaning that the estimated change is based on the data from these, while the remaining data are used to estimate the random variation between participants, visits, and days and thus contribute to degrees of freedom in the variance estimates.

This is the first real-world insight into outcomes with connected pen use in clinical practice. Data presented here were subject to acknowledged limitations, and larger, controlled follow-up studies are needed. Nonetheless, our findings suggest that connected pens such as the NovoPen ${ }^{\circledR} 6$ have the potential to improve glycemic control, decrease glucose variability and increase treatment concordance in people with T1D, addressing the large unmet need for optimal insulin treatment.

\section{Acknowledgments}

The authors thank Ann-Charlotte Mårdby (Novo Nordisk Sweden) and Melissa Voigt Hansen (Novo Nordisk A/S, Denmark) for their review of and input to the article and Francesca Hemingway and Victoria Jones from Watermeadow Medical (sponsored by Novo Nordisk) for providing medical writing and editorial support.

\section{Author Disclosure Statement}

P.A. has received research support or advisory board fees from Eli Lilly, Novo Nordisk, Roche, funding from Research and Development, Region Halland, and is an employee of Region Halland.

N.V.H., A.K., and J.B.M. are full-time employees of, and hold stock in, Novo Nordisk A/S.

J.H. has received advisory board fees from Abbott, Bayer, Sanofi, Novo Nordisk, Eli Lilly, MSD, and Boehringer Ingelheim and received consultancy fees from Sanofi, Novo Nordisk, and Boehringer Ingelheim.

\section{Funding Information}

Funding source: Novo Nordisk.

\section{Supplementary Material}

Supplementary Figure S1

Supplementary Figure S2

\section{References}

1. Osborn CY, Gonzalez JS: Measuring insulin adherence among adults with type 2 diabetes. J Behav Med 2016;39: 633-641.

2. Davies MJ, Gagliardino JJ, Gray LJ, et al.: Real-world factors affecting adherence to insulin therapy in patients with type 1 or type 2 diabetes mellitus: a systematic review. Diabet Med 2013;30:512-524. 
3. Peyrot M, Barnett AH, Meneghini LF, et al.: Insulin adherence behaviours and barriers in the multinational Global Attitudes of Patients and Physicians in Insulin Therapy study. Diabet Med 2012;29:682-689.

4. Cramer JA: A systematic review of adherence with medications for diabetes. Diabetes Care 2004;27:1218-1224.

5. Munshi MN, Slyne C, Greenberg JM, et al.: Nonadherence to insulin therapy detected by bluetooth-enabled pen cap is associated with poor glycemic control. Diabetes Care 2019; 42:1129-1131.

6. Schaper NC, Nikolajsen A, Sandberg A, et al.: Timing of insulin injections, adherence, and glycemic control in a multinational sample of people with type 2 diabetes: a cross-sectional analysis. Diabetes Ther 2017;8:1319-1329.

7. Randlov J, Poulsen JU: How much do forgotten insulin injections matter to hemoglobin a1c in people with diabetes? A simulation study. J Diabetes Sci Technol 2008;2: 229-235.

8. Munshi MN, Segal AR, Suhl E, et al.: Assessment of barriers to improve diabetes management in older adults: a randomized controlled study. Diabetes Care 2013;36:543549.

9. Hood KK, Peterson CM, Rohan JM, et al.: Association between adherence and glycemic control in pediatric type 1 diabetes: a meta-analysis. Pediatrics 2009;124:e1171e1179.

10. Spaans E, van Hateren KJJ, Groenier KH, et al.: Mealtime insulin bolus adherence and glycemic control in adolescents on insulin pump therapy. Eur J Pediatr 2018;177: 1831-1836.

11. Andrade CS, Ribeiro GS, Santos C, et al.: Factors associated with high levels of glycated haemoglobin in patients with type 1 diabetes: a multicentre study in Brazil. BMJ Open 2017;7:e018094.

12. Olinder AL, Kernell A, Smide B: Missed bolus doses: devastating for metabolic control in CSII-treated adolescents with type 1 diabetes. Pediatr Diabetes 2009;10:142148.

13. Nathan DM, Genuth S, Lachin J, et al.: The effect of intensive treatment of diabetes on the development and progression of long-term complications in insulin-dependent diabetes mellitus. N Engl J Med 1993;329:977-986.

14. Nathan DM, Cleary PA, Backlund JY, et al.: Intensive diabetes treatment and cardiovascular disease in patients with type 1 diabetes. N Engl J Med 2005;353:2643-2653.

15. Miller KM, Foster NC, Beck RW, et al.: Current state of type 1 diabetes treatment in the U.S.: updated data from the T1D Exchange clinic registry. Diabetes Care 2015;38:971978.

16. Welsh JB: Role of continuous glucose monitoring in insulin-requiring patients with diabetes. Diabetes Technol Ther 2018;20(Suppl 2):S242-S249.

17. Slattery D, Choudhary P: Clinical use of continuous glucose monitoring in adults with type 1 diabetes. Diabetes Technol Ther 2017;19(Suppl 2):S55-S61.

18. Bergenstal RM, Ahmann AJ, Bailey T, et al.: Recommendations for standardizing glucose reporting and analysis to optimize clinical decision making in diabetes: the Ambulatory Glucose Profile (AGP). Diabetes Technol Ther 2013;15:198-211.

19. Lind M, Polonsky W, Hirsch IB, et al.: Continuous glucose monitoring vs conventional therapy for glycemic control in adults with type 1 diabetes treated with multiple daily in- sulin injections: the GOLD randomized clinical trial. JAMA 2017;317:379-387.

20. Battelino T, Conget I, Olsen B, et al.: The use and efficacy of continuous glucose monitoring in type 1 diabetes treated with insulin pump therapy: a randomised controlled trial. Diabetologia 2012;55:3155-3162.

21. Heinemann L, Freckmann G, Ehrmann D, et al.: Real-time continuous glucose monitoring in adults with type 1 diabetes and impaired hypoglycaemia awareness or severe hypoglycaemia treated with multiple daily insulin injections (HypoDE): a multicentre, randomised controlled trial. Lancet 2018;391:1367-1377.

22. Danne T, Nimri R, Battelino T, et al.: International consensus on use of continuous glucose monitoring. Diabetes Care 2017;40:1631-1640.

23. Harvey RA, Dassau E, Zisser H, et al.: Design of the glucose rate increase detector: a meal detection module for the health monitoring system. J Diabetes Sci Technol 2014;8: 307-320.

24. Bailey TS, Stone JY: A novel pen-based Bluetooth-enabled insulin delivery system with insulin dose tracking and advice. Expert Opin Drug Deliv 2017;14:697-703.

25. Heisler M, Bouknight RR, Hayward RA, et al.: The relative importance of physician communication, participatory decision making, and patient understanding in diabetes selfmanagement. J Gen Intern Med 2002;17:243-252.

26. Ritholz MD, Beverly EA, Brooks KM, et al.: Barriers and facilitators to self-care communication during medical appointments in the United States for adults with type 2 diabetes. Chronic Illn 2014;10:303-313.

27. Battelino T, Danne T, Bergenstal RM, et al.: Clinical targets for continuous glucose monitoring data interpretation: recommendations from the international consensus on time in range. Diabetes Care 2019;42:1593-1603.

28. Vigersky RA, McMahon C: The relationship of hemoglobin $\mathrm{A} 1 \mathrm{C}$ to time-in-range in patients with diabetes. Diabetes Technol Ther 2019;21:81-85.

29. Beck RW, Bergenstal RM, Cheng P, et al.: The relationships between time in range, hyperglycemia metrics, and HbA1c. J Diabetes Sci Technol 2019;13:614-626.

30. Pfutzner A, Weissmann J, Mougiakakou S, et al.: Glycemic variability is associated with frequency of blood glucose testing and bolus: post hoc analysis results from the ProAct study. Diabetes Technol Ther 2015;17:392-397.

31. Ceriello A, Esposito K, Piconi L, et al.: Oscillating glucose is more deleterious to endothelial function and oxidative stress than mean glucose in normal and type 2 diabetic patients. Diabetes 2008;57:1349-1354.

32. Esposito K, Nappo F, Marfella R, et al.: Inflammatory cytokine concentrations are acutely increased by hyperglycemia in humans: role of oxidative stress. Circulation 2002;106:2067-2072.

33. Hirakawa Y, Arima H, Zoungas S, et al.: Impact of visit-tovisit glycemic variability on the risks of macrovascular and microvascular events and all-cause mortality in type 2 diabetes: the ADVANCE trial. Diabetes Care 2014;37:23592365.

34. Ceriello A, Kilpatrick ES: Glycemic variability: both sides of the story. Diabetes Care 2013;36(Suppl 2):S272-S275.

35. Sartore G, Chilelli NC, Burlina S, et al.: The importance of $\mathrm{HbA} 1 \mathrm{c}$ and glucose variability in patients with type 1 and type 2 diabetes: outcome of continuous glucose monitoring (CGM). Acta Diabetol 2012;49(Suppl 1):S153-S160. 
36. Dandona P: Minimizing glycemic fluctuations in patients with type 2 diabetes: approaches and importance. Diabetes Technol Ther 2017;19:498-506.

37. Runge AS, Kennedy L, Brown AS, et al.: Does time-inrange matter? Perspectives from people with diabetes on the success of current therapies and the drivers of improved outcomes. Clin Diabetes 2018;36:112-119.

38. Doggrell SA, Chan V: Adherence to insulin treatment in diabetes: can it be improved? J Diabetes 2015;7:315-321.

39. Burdick J, Chase HP, Slover RH, et al.: Missed insulin meal boluses and elevated hemoglobin A1c levels in children receiving insulin pump therapy. Pediatrics 2004; 113(Pt 1):e221-e224.

40. Norlander LM, Anderson SA, Levy CJ, et al.: Late and missed meal boluses with multiple daily insulin injections. Diabetes 2018;68(Suppl 1):A259.

41. Kavanos P, Van den Aardweg S, Schurer W: Diabetes expenditure, burden of disease and management in $5 \mathrm{EU}$ countries. www.lse.ac.uk/business-and-consultancy/consulting/ assets/documents/diabetes-expenditure-burden-of-diseaseand-management-in-5-eu-countries.pdf (accessed December 2020).

42. Harrison XA, Donaldson L, Correa-Cano ME, et al:: A brief introduction to mixed effects modelling and multimodel inference in ecology. PeerJ 2018;6:e4794.

Address correspondence to: Peter Adolfsson, MD, PhD Department of Pediatrics The Hospital of Halland, Kungsbacka Tölövägen 5 Kungsbacka 43480 Sweden

E-mail: peter.adolfsson@ @regionhalland.se 